\title{
In vitro evaluation of Salinomycin addition in wheat straw based total mixed diets on rumen fermentation, methanogenesis and dry matter degradability in buffalo
}

\author{
Sunil K. Sirohi, Navneet Goel \\ Nutrition Biotechnology Lab, \\ Animal Biotechnology Centre, Dairy Cattle Nutrition Division \\ National Dairy Research Institute, Karnal-132001, India \\ Corresponding author: S K Sirohi, email: sirohisk@gmail.com \\ Received: 27-03-2012, Accepted: 16-04-2012, Published Online: 29-07-2012
}

doi: $10.5455 /$ vetworld.2012.609-613

\begin{abstract}
Aim: The aim of the current study was to evaluate the effect of salinomycin in vitro on methanogenesis and rumen fermentation.

Materials and Methods: Different levels of $(0,10,15$ and $20 \mathrm{ppm})$ salinomycin were checked for their effect on in vitro methanogenesis and rumen fermentation on three wheat straw based diets i.e. low fiber diet (LFD, 40R:60C), medium fiber diet (MFD, 50R:50C) and high fiber diet (HFD, 60R:40C). Evaluation of salinomycin was carried out using in vitro gas production technique. Methane production and individual fatty acids were estimated by Gas Chromatography.

Results: Results of different levels of salinomycin on in vitro methanogenesis indicated that the maximum methane reduction (38.14\% in term of $\mathrm{mM} / \mathrm{gDM}$ ) was noticed in HFD at $20 \mathrm{ppm}$ level. IVDMD showing increasing trend with an increasing concentration of salinomycin with HFD and LFD, while shown decreasing trend with MFD respectively. Protozoal population significantly decreased by addition of salinomycin in all diets.

Conclusion: The results of salinomycin evaluation in the current study can be implicated to mitigate the methane production, thus saving the feed energy loss and the accumulation of green house gases in environment.

Key Words: In vitro gas production technique, IVDMD, Methanogenesis, Salinomycin
\end{abstract}

To cite this article: Sirohi SK, Goel N (2012) In vitro evaluation of Salinomycin addition in wheat straw based total mixed diets on rumen fermentation, methanogenesis and dry matter degradability in buffalo, Vet World, 5(10): 609-613, doi: 10.5455/vetworld.2012.609-613

\section{I ntroduction}

Ionophores are antimicrobial compounds that are commonly used in the diets of monogastric and poultry for increasing the feed conversion efficiency and prevention of some diseases. Commonly used ionophores are monensin, lasalocid, laidlomycin, salinomycin and narasin. Salinomycin is a polyether antibiotic and produced by a strain of streptomyces albus (ATCC 21838). The main physiochemical characteristics of salinomycin are, molecular weight, 750; molecular formula, $\mathrm{C}_{42} \mathrm{H}_{70} \mathrm{O}_{11}$; melting poin, 112.5 to $113.5^{\circ} \mathrm{C}$; pKa, 6.40 ; cation affinity, $\mathrm{K}>\mathrm{Na}>\mathrm{Ca}, \mathrm{Mg}$; cation transport activity, $\mathrm{Na}>\mathrm{K}>$ $\mathrm{Ca}, \mathrm{Mg}[1,2]$. Salinomycin has been shown the activity against gram-positive bacteria, including mycobacteria and some filamentous fungi. However, no activity has been found against gram-negative bacteria or yeasts [1].

A number of study have found that salinomycin to be effective in enhancing both rate of gain and feed efficiency in feedlot cattle $[3,4,5]$. It is also effective in the treatment of coccidial infections of poultry and cattle [6].

Ionophores inhibit gram positive bacteria, which subsequently alters ruminal fermentation. When the gram negative bacteria predominate in the rumen, less methane is produced and more propionate is produced as reported by several workers $[7,8]$. Methane is one of the most potent GHG which is produced from enteric fermentation in ruminants. Therefore, present study was planned to investigate the effect of salinomycin supplementation in different diets on rumen fermentation and methanogenesis in vitro.

\section{Materials and methods}

Preparation of Diets: To study the effect of salinomycin on rumen fermentation and methane production three diets were prepared with different roughage concentrate ratio i.e. high fiber diet (HFD, 
60R:40C), medium fiber diet (MFD, 50R:50C) and low fiber diet (LFD, 40R:60C) and milled to pass through $1 \mathrm{~mm}$ sieve and used as substrate. Source of roughage and concentrate were wheat straw and normal farm concentrate having about $20 \%$ crude protein and $70 \%$ total digestible nutrients (TDN). The concentrate part comprised of maize $(33 \%)$, GNC (21\%), mustard cake (12\%), wheat bran $(20 \%)$, deoiled rice bran (11\%), mineral mixture (2\%) and salt $(1 \%)$.

Treatments and experimental design: Four levels i.e. $0 \mathrm{ppm}, 10 \mathrm{ppm}, 15 \mathrm{ppm}$ and $20 \mathrm{ppm}$ of salinomycin were added to the different wheat straw based HFD, MFD and LFD diets. All the treatment combinations were arranged in $4 \times 3$ factorial arrangements in randomized block designs with three replicates. Set was also incubated devoid of substrate with and without additive, which served as blanks for particular treatment and values were corrected for different parameters with these blanks.

Preparation of Inoculums and In Vitro Gas Production: Rumen liquor (RL) was obtained from fistulated adult male buffaloe (Bubalus bubalis) kept on standard diet (60 parts roughage: 40 parts concentrate) before one hour of morning feeding into a pre-warmed insulated flask and brought into the laboratory. Permission for taking rumen liquor from male fistulated buffaloes already taken from Animal ethics committee of institute. Then rumen liquor filtered through four layers of muslin cloth and the required amount of strained rumen liquor used as a source of inoculum.

The incubation medium was prepared as per previously described method [9]. In vitro studies were carried out in $100 \mathrm{ml}$ calibrated glass syringes containing $200 \pm 10 \mathrm{mg}$ of milled $(1 \mathrm{~mm})$ three type wheat straw based diet [9].

Plungers of syringes applied with petroleum jelly for smooth movement and stop any leakage. The $30 \mathrm{ml}$ incubation medium was dispensed anaerobically in each syringe and before incubation, different levels of salinomycin was added by small syringe into $100 \mathrm{ml}$ syringes individually and mixed uniformly. Syringes were closed using clamps and were incubated at $39 \pm 0.5^{\circ} \mathrm{C}$ for $24 \mathrm{~h}$ in temperature controlled incubator cum shaker.

Total gas production and methane estimation: After $24 \mathrm{~h}$ incubation, gas production was recorded with the displacement of piston during incubation. The gas produced due to fermentation of substrate was calculated by subtracting gas produced in blank syringe (containing no substrate, but only the inoculum and buffer) from total gas produced in the syringe containing substrate and inoculum.

For methane estimation, representative of gas was sampled from the headspace of syringe in an airtight syringe and injected into Nucon-5765 gas chromatograph equipped with flame ionization detector (FID) and stainless steel column packed with Porapak-Q (length 6';o.d.1/8" i.d. 2 mm; mesh range 80-100). The gas flow rates for carrier gas (nitrogen), hydrogen and air were 30,30 and $300 \mathrm{ml} / \mathrm{min}$, respectively. Temperature of injector oven, column oven and detector were 40,50 and $50^{\circ} \mathrm{C}$, respectively. For methane estimation, each gas sample $(250 \mu \mathrm{l})$ was manually injected using Hamilton airtight syringe.

Methane content in sample was calculated by external calibration, using a certified gas standard mixture of $50 \% \quad \mathrm{CH}_{4}$ and $50 \% \quad \mathrm{CO}_{2}$ (Spantech calibration gas, Surrey, England).

Methane production $(\mathrm{ml})=$ Total gas produced (ml) $x \%$ methane in the sample

In vitro true Dry matter degradability: To estimate true DM degradability of feed sample of each syringe containing residues after incubation was estimated as per method [10].

Proximate analyses and cell wall constituents: The proximate analysis of substrate was carried out as per the methods of [11]. The cell wall constituents of substrates were determined according to suggested method [10].

Estimation of ammonia nitrogen and individual volatile fatty acid (IVFA): After the end of incubation, fermented material was transferred into centrifuge tubes and centrifuge at $3000 \mathrm{rpm}$ for ten minutes, than supernatant of each syringe including that of blank was collected in vials used for ammonia nitrogen $\left(\mathrm{NH}_{3}-\mathrm{N}\right)$ and individual volatile fatty acid (IVFA).

For $\mathrm{NH}_{3}-\mathrm{N}$ estimation, $5 \mathrm{ml}$ of supernatant was taken in tube mixed with $12 \mathrm{ml} 1 \mathrm{~N} \mathrm{NaOH}$ and steam passed using KEL PLUS-N analyzer (Pelican, India) and the $\mathrm{NH}_{3}$ evolved was collected in conical flask containing boric acid solution having mixed indicator and titrated against $\mathrm{N} / 100 \mathrm{H}_{2} \mathrm{SO}_{4}$.

Individual volatile fatty acids (IVFAs) were estimated by taking $1 \mathrm{ml}$ of the supernatant treated with $25 \%$ meta-phosphoric $(4 \mathrm{ml}$ ) prepared in $1 \mathrm{~N}$ sulphuric acid and kept for 3-4 $\mathrm{h}$ at ambient temperature [12]. Thereafter, it was centrifuged $(3,000$ rpm for $10 \mathrm{~min}$ ) and clear supernatant was collected and stored at $-20^{\circ} \mathrm{C}$ until analyzed. IVFAs were 
In vitro evaluation of Salinomycin addition in wheat straw based total mixed diets on rumen fermentation

Table-1. Physical and chemical composition of wheat straw based diets used as substrate in in vitro incubation

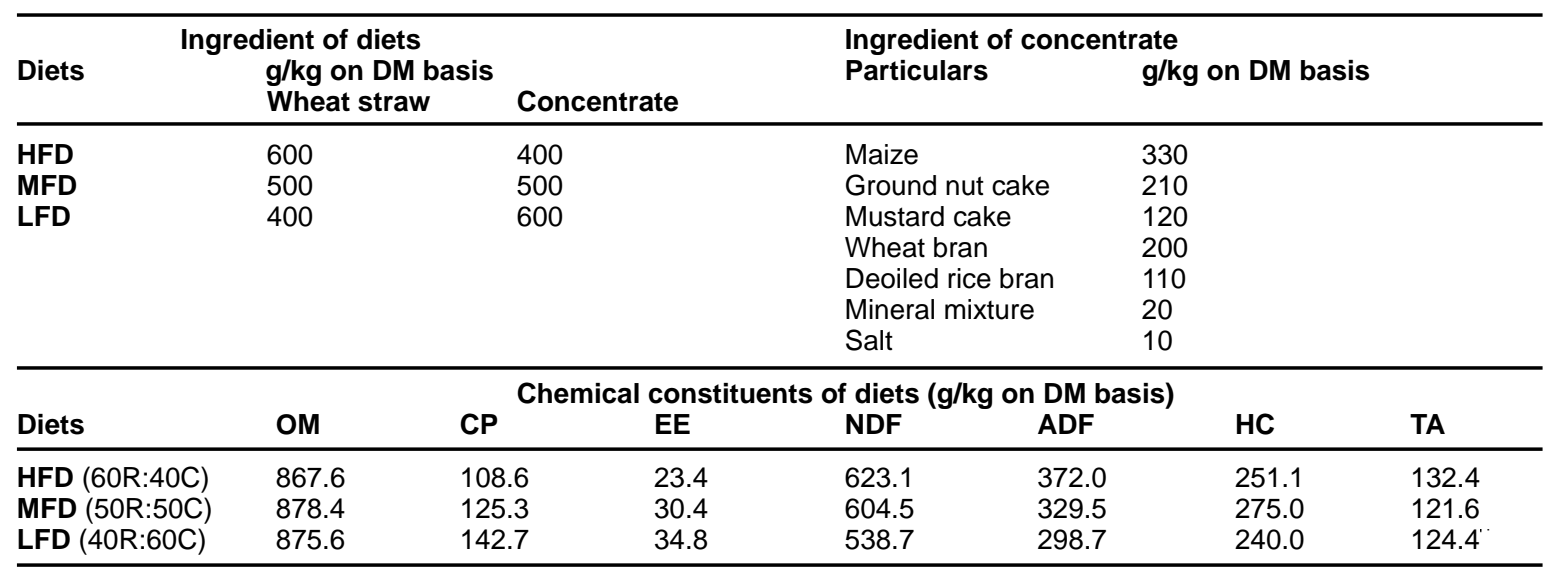

HFD, high fiber diet; MFD, medium fiber diet; LFD, low fiber diet; R, roughage; $C$, concentrate; OM, organic matter; CP, crude protein; EE, ether extract; NDF, natural detergent fiber; ADF, acid detergent fiber; HC, hemicelluloses; TA, total ash

estimated using gas chromatograph (Nucon 5700, India) equipped with flame ionization detector (FID) and stainless steel column (length 4'; o.d 1/8"; i.d $2 \mathrm{~mm}$ ) packed with Chromosorb-101.

Temperature of injection port, column and detector was set at 200,180 and $210^{\circ} \mathrm{C}$, respectively. The flow rate of carrier gas (nitrogen) through the column was $40 \mathrm{ml} / \mathrm{min}$ and the flow rates of hydrogen gas and air through FID were 30 and $300 \mathrm{ml} / \mathrm{min}$. respectively.

Sample $(2 \mu)$ was injected through the injection port using Hamilton syringe $(10 \mu)$. Individual VFA's of the samples were identified on the basis of their retention time and their concentration (mM) calculated by comparing the retention time as well as the peak area of standards after deducting the corresponding blank values.

Protozoa counting: The stained protozoa was diluted (if needed) and counted by Haemocytometer as per prescribed method [13].

Statistical analysis: Experimental data of different parameters were analyzed in complete randomized block design for analysis of variance and standard error of means [14].

\section{Results and Discussion}

The physical and chemical composition of all the three diets was given in table 1. Results of different levels of salinomycin on in vitro rumen fermentation and methanogenesis were shown in Table 2.

Effect of salinomycin on IVDMD was significant for all three diets. In HFD, digestibility was maximum increased $(10.18 \%)$ at $20 \mathrm{ppm}$ level than $7.80 \%$ in
LFD at $10 \mathrm{ppm}$ level, while decreased slightly with increasing concentration of salinomycin in case of MFD. A reduction in methane production $(\mathrm{ml} / \mathrm{gDM}$, $\mathrm{mM} / \mathrm{gDM}, \mathrm{mM} / \mathrm{gDDM}$ ) was seen in all the diets with addition of salinomycin. Methane production percentage decreased with increasing concentration of salinomycin in all diets. Results showed the highest methane reduction $(38.14,30.14$ and $27.68 \%)$ at $20 \mathrm{ppm}$ level in HFD, MFD and LFD, when expressed in $\mathrm{mM} / \mathrm{gDM}$ respectively. Similar effect of salinomycin on methane production was also found by other workers $[15,16]$.

The propionic acid concentration $(\mathrm{mM} / \mathrm{l})$ increased with increasing dosage in all the three diet. The increase in propionic acid concentration was $48.43 \%$ at $15 \mathrm{ppm}$ level in MFD, $19.95 \%$ at $20 \mathrm{ppm}$ level in HFD and slightly changes in LFD. A non significant $(\mathrm{P} \leq 0.05)$ change in acetate concentration was observed in all diets. Acetate concentration increased in almost all cases except HFD, although the increase was non significant. A significant effect of salinomycin on butyrate concentration was seen in present study. Slight change in $\mathrm{A} / \mathrm{P}$ ratio was observed in all cases except 20 ppm level in HFD, where the maximum reduction $(47.20 \%)$ was found. The similar results were observed during salinomycin supplementation were consistent with the earlier findings of numerous researchers [17-19]. A non significant $(\mathrm{P} \leq 0.05)$ reduction in $\mathrm{NH}_{3}-\mathrm{N}$ was observed due to salinomycin supplementation. The concentration of ammonia nitrogen increased with increasing concentrations of salinomycin in HFD and LFD while, decreased in MFD. The maximum reduction was $(20 \%)$ found in MFD at 15 ppm level.

In present experiment, a significant $(\mathrm{P} \leq 0.05)$ 
In vitro evaluation of Salinomycin addition in wheat straw based total mixed diets on rumen fermentation

Table-2. Rumen fermentation parameters as affected by Salinomycin supplementation in different diets

\begin{tabular}{|c|c|c|c|c|c|c|c|c|c|c|c|}
\hline Diets & $\begin{array}{l}\text { Dose } \\
\text { (ppm) }\end{array}$ & $\begin{array}{l}\text { IVDMD } \\
(\%)\end{array}$ & $\begin{array}{c}\mathrm{CH4} \\
\text { (ml/gDM) }\end{array}$ & $\begin{array}{c}\mathrm{CH4} \\
\text { (mM/gDM) }\end{array}$ & $\begin{array}{c}\mathrm{CH4} \\
\text { (mM/gDDM) }\end{array}$ & $\begin{array}{l}\text { Acetate } \\
(\mathrm{mM} / \mathrm{l})\end{array}$ & $\begin{array}{l}\text { Propionate } \\
\text { (mM/l) }\end{array}$ & $\begin{array}{l}\text { Butyrate } \\
\text { (mM) }\end{array}$ & $A: P$ & $\begin{array}{c}\mathrm{NH}_{3}-\mathrm{N} \\
(\mathrm{mg} / 100 \mathrm{ml})\end{array}$ & $\begin{array}{c}\text { Protozoa } \\
\left(\times 10^{5} \text { cells } / \mathrm{ml}\right)\end{array}$ \\
\hline HFD & 00 & 60.50 & 34.74 & 3.45 & 2.86 & 72.90 & 11.68 & 8.20 & 6.25 & 14.00 & 5.50 \\
\hline \multirow{2}{*}{ (60R:40C) } & 10 & 63.00 & 27.83 & 2.77 & 1.75 & 68.09 & 13.84 & 3.50 & 5.15 & 14.00 & 4.60 \\
\hline & 20 & 66.66 & 21.38 & 2.13 & 1.25 & 71.95 & 14.01 & 6.20 & 3.30 & 14.93 & 2.00 \\
\hline MFD & 00 & 68.66 & 35.61 & 3.54 & 2.13 & 64.60 & 10.88 & 5.10 & 6.34 & 14.00 & 3.50 \\
\hline (50R:50C) & 10 & 65.83 & 36.36 & 3.62 & 2.25 & 94.36 & 11.26 & 4.69 & 5.23 & 11.66 & 1.00 \\
\hline \multirow[t]{3}{*}{$(40 \mathrm{R}: 60 \mathrm{C})$} & 10 & 76.00 & 27.55 & 2.74 & 1.60 & 75.60 & 13.17 & 4.82 & 4.54 & 12.13 & 2.50 \\
\hline & 15 & 71.00 & 26.69 & 2.65 & 1.61 & 60.70 & 11.62 & 8.21 & 4.73 & 13.53 & 3.00 \\
\hline & 20 & 70.50 & 25.65 & 2.55 & 1.47 & 79.20 & 14.72 & 11.27 & 4.67 & 13.06 & 1.50 \\
\hline \multirow[t]{3}{*}{ SEM } & Dose & 2.08 & 1.09 & 0.04 & 0.07 & NS & NS & 0.05 & 0.26 & NS & 0.46 \\
\hline & Diet & 2.40 & 1.26 & 0.04 & 0.09 & NS & NS & 0.05 & 0.29 & NS & 0.52 \\
\hline & D*D & $\star \star *$ & $\star \star$ & $* *$ & $\star *$ & NS & NS & $\star *$ & $* *$ & NS & ** \\
\hline
\end{tabular}

* Significant at $\mathrm{P} \leq 0.05$; ** Significant at $\mathrm{P} \leq 0.01$; SEM, Standard Error of Means; IVDMD, in vitro dry matter digestibility; $\mathrm{CH} 4$, methane; $\mathrm{A}: \mathrm{P}$, acetate to propionate ratio; $\mathrm{NH} 3-\mathrm{N}$, ammonia nitrogen

reduction in protozoal number was observed with the increasing concentration of salinomycin. At $20 \mathrm{ppm}$ level of salinomycin, maximum reduction in protozoa number was found i.e. $63.63,85.71$ and $57.15 \%$ in HFD, MFD and LFD, respectively.

\section{Conclusions}

On comparing the effects of salinomycin on three diets, it was observed that the propionate production increased with the increasing dosage of salinomycin. On the other hand the methane production was reduced significantly and highest decrease was noticed at $20 \mathrm{ppm}$. This indicates a shift in ruminal fermentation pattern. The hydrogen was shifted towards propionate production. IVDMD was increased with the increasing concentration of salinomycin on high and low fibre diets but decreased slightly in medium fibre diet.

\section{Author's contribution}

N. Goel conducted experiment, prepared tables and S.K. Sirohi planned the experiment, involved in statistical analysis and drafting of the paper. Both the authors read and approved the final manuscript.

\section{Acknowledgements}

Authors would like to thank and acknowledge for the grant provided by Department of Biotechnology, Ministry of Science and Technology, Govt. of India, New Delhi-100012 to carry out this research work.

\section{Competing interest}

Authors declares that they have no competing interest.

\section{References}

1. Miyazaki, Y., Shibuya, M., Sugawara, H., Kawaguchi,
O., Hirose, C., Nagatsu, J. and Esumi, S. (1974). Salinomycin, a new polyether antibiotic. J. Antibiot. 27: 814 .

2. Mitani, M., Yamanishi, T. and Miyazaki, Y. (1975). Salinomycin: A new monovalent cation ionophore. Biochem. Biophys. Res. Commun. 66: 1231.

3. Price M.M., Einkamerer O.B., Witt F.H. de, Greyling J.P.C. and Fair, M.D. (2009). The effect of dietary ionophores on feedlot performance of lambs. S. Afr. J. Anim. Sci. 39(5): 141-144.

4. Merchen, N.R. and Berger, L.L. (1985). Effect of salinomycin level on nutrient digestibility and ruminal characteristics of sheep and feedlot performance of cattle. J. Anim. Sci. 60: 1338.

5. Owens, F.N., Gill, D.R., Weekley, D.C. and Lucas, D.M. (1982). Salinomycin levels for feedlot steers. $J$. Anim. Sci. 55 (Suppl.1): 448.

6. Merchen, N.R. and Berger, L.L. (1985). Effect of salinomycin level on nutrient digestibility and ruminal characteristics of sheep and feedlot performance of cattle. J. Anim. Sci. 60: 1338.

7. Sirohi. Sunil K., Pandey Neha, Singh, B., Mohini Madhu, Puniya, A.K., Kundu, S.S., Thube Harshala (2011). Effect of Monensin and Anthraquinone Supplementation on Rumen Fermentation and Methane Production in vitro. The Indian Journal of Animal Science 81 (8).

8. Bharat Kumar M., Sriram P. and Mathuram L.N (2008). Effect of monensin on in vitro rumen fermentation. Indian Veterinary Journal 85: 1268-71.

9. Menke, K.H. and Steingass, H. (1988). Estimation of the energetic feed value obtained from chemical analysis and in vitro gas production using rumen fluid. Anim. Res. Dev. 28:7-55.

10. Van Soest, P.J., Robertson, J.B. and Lewis, B.A. (1991). Methods for dietary fiber, neutral detergent fiber and non starch polysaccharides in relation to animal nutrition. Journal of Dairy Science 74: 3583-3597.

11. Association of Official Analytical Chemists www.veterinaryworld.org 
(1995). Official Methods of Analysis, $1^{\text {th }}$ ed., chapter 4,p. 13. Arlington, VA.

12. Erwin, E.S., Macro, G.A.and Emery, E.M. (1961). Volatile fatty acid analysis of blood and rumen fluid by Gas chromatograph. Journal of Dairy Science, 44: 1768-1771.

13. Dehority, Burk, A. (1984). Evaluation of subsampling and fixation procedures used for counting rumen protozoa. Applied and Environmental Microbiology 48: 182-185.

14. Snedecor, G.W. and Cochran, W.G. (1968). Statistical Methods, 5th ed. Iowa State Univ. Press, Ames., I.A.

15. Wakita, M., Masuda, T. and Hoshino, S. (1986). Effects of Salinomycin on the Gas Production by Sheep Rumen Contents in vitro. J. Anim. Phys. Anim. Nutr. 56: 243-251.

16. Kobayashi, Y., Wakita, M. and Hoshino, S. (1988).
Persistency of Salinomycin Effect on Ruminal Fermentation. Nutr. Rep. Int. 38:987-999.

17. Olumeyan, D.B., Nagaraja, T.G., Miller, G.W., Frey, R.A. and Boyer, J.E. (1986). Rumen microbial changes in cattle fed diets with or without salinomycin. Appl. Environ. Microbiol. 51:340- 345.

18. McAllister, T.A., Moustafa, S.M.S., Cheng, K.J., Newbold, C.J., McKain, N. and Wallace, R.J. (1994). Effect of salinomycin onfermentation and nitrogen metabolism in the artificial rumen. Can. J. Anim. Sci. 74: 575 .

19. Bharath Kumar, M., Sriram, P., Vijayarani, K., Vijaya kumar, C. and Mathuram, N. (2010). Effects of salinomycin and sodium fumarate on rumen fermentation using rumen simulation technique. Indian Journal of Animal Sciences 80 (7): 638-641, July 2010. 